DEMOGRAPHIC RESEARCH

VOLUME 41, ARTICLE 21, PAGES 593-616 PUBLISHED 28 AUGUST 2019

http://www.demographic-research.org/Volumes/Vol41/21/

DOI: 10.4054/DemRes.2019.41.21

Reflection

\title{
Introduction to the special collection on spatial mobility, family dynamics, and gender relations
}

\section{Sergi Vidal}

\section{Johannes Huinink}

This publication is part of the Special Collection on "Spatial Mobility, Family Dynamics, and Gender Relations," organized by Guest Editors Sergi Vidal and Johannes Huinink.

(C) 2019 Sergi Vidal \& Johannes Huinink.

This open-access work is published under the terms of the Creative Commons Attribution 3.0 Germany (CC BY 3.0 DE), which permits use, reproduction, and distribution in any medium, provided the original author(s) and source are given credit.

See https://creativecommons.org/licenses/by/3.0/de/legalcode. 


\section{Contents}

1 Introduction $\quad 594$

2 Spatial mobility, family dynamics, and gender relations: Research 596

background and further avenues

$2.1 \quad$ Spatial mobility and the dynamics of families 596

$2.2 \quad$ Gender inequality in couple-household mobility 598

$\begin{array}{lll}2.3 & \text { Further avenues } & 601\end{array}$

3 Contents of the SC 603

4 Acknowledgements $\quad 606$

$\begin{array}{ll}\text { References } & 607\end{array}$ 


\title{
Introduction to the special collection on spatial mobility, family dynamics, and gender relations
}

\author{
Sergi Vidal ${ }^{1}$ \\ Johannes Huinink ${ }^{2}$
}

\begin{abstract}
BACKGROUND

There is growing evidence that spatial mobility has an impact on and is driven by family dynamics and gender relations. In contexts where family diversity and complexity have increased and gender inequalities persist, it is particularly urgent that we advance our understanding of decisions regarding spatial mobility and of its patterns and outcomes, in relation to families and gender.
\end{abstract}

\section{CONTRIBUTION}

This special collection highlights the importance of and presents novel findings on the interplay between spatial mobility, family dynamics, and gender relations. It unites new research perspectives that expand existing horizons with rigorous and innovative empirical studies. Contributions to this special collection deal with a number of underresearched areas that include, but are not restricted to, non-coresident family ties and gender differences in willingness to move, circular mobility patterns, and the nonlabour market outcomes of family migration. The insights contained in the articles in this collection not only clarify concrete associations but also offer roadmaps for revealing the mechanisms that explain them.

\footnotetext{
${ }^{1}$ Centre for Demographic Studies, Barcelona, Spain. Email: svidal@ced.uab.es.

${ }^{2}$ University of Bremen, Germany.
} 


\section{Introduction}

The aim of this special collection (SC) is to highlight the importance of and expand our knowledge on the interplay between spatial mobility, family life courses and contexts, and gender relations. ${ }^{3}$ Growing research evidence suggests that, at all stages from early through later life, spatial mobility and family are intertwined in one way or another (Cooke 2008a, 2013; Aybek, Huinink, and Muttarak 2014; Wagner and Mulder 2015). Migration within and across countries, residential relocations, and circular mobility (e.g., commuting) often respond to changes in household and family dynamics over the life course, for example, those related to leaving the parental home, moving in with a partner, moving to a larger home to accommodate a growing family, or moving out after union dissolution (Mulder and Wagner 1993; Clark and Huang 2003; Geist and McManus 2008; Kulu 2008; Vidal, Huinink, and Feldhaus 2017). The associations also extend to more nuanced aspects of family contexts, such as men's and women's ability to accept jobs at a given distance from the family home and their proximity to family ties outside the household (Mulder 2007; Mulder and Cooke 2009). In addition, new patterns of frequent, recurrent, and seasonal mobility have emerged in recent decades, partly due to the increasing diversity of family forms and living arrangements, including couples living apart together and patchwork families, among other developments (Coulter, van Ham, and Findlay 2016).

Other research highlights relevant gendered patterns in spatial mobility that are substantial at the time of union and family formation and thereafter (Brandén and Haandrikman 2018). The pervasive and persistent gender inequalities in the labour market that permeate spatial mobility decisions are particularly relevant to the labour outcomes of men and women in family households. Compared to men (and single women), partnered women and mothers cover shorter commuting distances, are less likely to lead long-distance household relocations for a job and, when following their partners in a job-related relocation, often experience lasting negative impacts on their employment and earnings (Boyle et al. 2003; Boyle, Feng, and Gayle 2009; De Jong and Graefe 2008; Cooke et al. 2009). Research has drawn attention to the persistence of women's domestic roles and secondary-earner status within families to explain observed gender differences in spatial mobility patterns and outcomes (Halfacree 1995; Cooke 2008b).

Despite the invaluable contributions of past research, important gaps remain in our knowledge and understanding of contemporary family and gender relations as they relate to the study of spatial mobility (and immobility). For instance, while research

\footnotetext{
${ }^{3}$ This SC draws on selected pieces of research from established and early-career researchers who contributed to the symposium titled "Spatial mobility, family dynamics and gender inequalities" held in Bremen (Germany) in late March 2017, and organized by Johannes Huinink, Sergi Vidal, and Tim Schröder.
} 
focuses on spatial mobility as a discrete relocation event, the long-term sequences of mobility and immobility and the patterns of circular mobility that are increasingly relevant for contemporary families (e.g., commuting partnerships, multilocal family arrangements) remain poorly theorised and under-researched. Also, despite the vast body of research on gender inequalities in couples' spatial mobility, we still know little about the collective household decisions that often lead to negative post-relocation labour market outcomes among partnered women, and about whether their career losses are compensated by gains in nonlabour market outcomes. Given that the motivations for and consequences of spatial mobility are rarely individual but involve the lives of others, we should seek to know more about how mobility decisions and outcomes relate not only to household members but also to family ties outside the household and other social contacts.

This SC underscores the need to further integrate spatial mobility, families, and gender within existing research programmes, echoing previous calls to put family and gender centre stage in spatial mobility research due to their growing importance for mobility patterns, decisions, and outcomes. The six papers in this SC combine new research perspectives that extend our existing horizons through rigorous and innovative empirical studies. Conceptually, these contributions extend the dominant approaches that focus on nuclear families and household members to incorporate non-coresident family ties into spatial mobility research. The empirical research papers exploit longitudinal data collections, using fit-for-purpose analytical tools to offer new evidence on the role of gender in family migration decision-making processes. They also offer insights into the spatial constraints on women and the commuting behaviour of family households as well as the nonlabour market outcomes of family relocations for men and women. Insights from the articles in this SC not only clarify concrete associations but also suggest strategies for revealing the mechanisms that explain them.

In the remainder of this introduction to the SC, we briefly review the literature, highlighting research avenues that expand our understanding of the interplay between spatial mobility, family dynamics, and gender relations. Then we outline the specific contributions of each paper in this SC. ${ }^{4}$

\footnotetext{
${ }^{4}$ This SC and its contributions focus on spatial mobility within national borders, however, we endorse calls to conceptualise international and internal mobility as two sides of the same coin (King and Skeldon 2010).
} 


\section{Spatial mobility, family dynamics, and gender relations: Research background and further avenues}

Rossi's (1980 [1955]) prominent early study of family mobility considered that spatial mobility performed an important function by adjusting the household's place of residence to its housing needs and desired type of environment. This approach to spatial mobility aligned well with a standard family life course and with the dominance of the male-breadwinner and female-homemaker household arrangement. Rossi approached spatial mobility from a life cycle perspective, with residential changes occurring according to age-normative stages; he also assumed that households made unitary decisions that supported the traditional nuclear family in accordance with normative gender beliefs. This approach grew less fitting over time, as women's expanding economic roles progressively challenged the prominence of the male-breadwinner model. Additionally, pervasive changes in family attitudes and behaviour (throughout the second half of the $20^{\text {th }}$ century) hindered the formation and stability of families, giving rise to a greater diversity of family forms, including lone-parent and reconstituted families. In response to these and other societal changes, research literature emerged to address the role of family dynamics and gender relations in contexts where, on the one hand, the family life course had become increasingly destandardised and, on the other, couple relocations took place alongside rising female labour force participation. While these and other related bodies of literature are voluminous, we will focus on only a few relevant aspects here and refer the reader to more exhaustive literature reviews for further insights.

\subsection{Spatial mobility and the dynamics of families}

The growing prominence of family dynamics in spatial mobility research dates back to the early 1990s and can be linked to the adoption of the life course as a conceptual and methodological framework. The increasing availability of longitudinal data also enabled analyses of the timing and sequencing of family events in relation to relocation events, above and beyond the role of simple family status (Kulu and Milewski 2007; Bailey 2009; Aybek, Huinink, and Muttarak 2014).

Earlier studies empirically confirmed that family events are critical predictors of spatial mobility. This research revealed strong associations between the timing of residential relocations and the timing of marriage, parenthood, and childbirths. It was, in many instances, interpreted using behavioural models where spatial mobility functions as a mechanism for adjusting to changing household situations and family roles (Courgeau 1985; Mulder and Wagner 1993; Mulder and Hooimeijer 1999). 
Evidence also suggested that residential mobility around the time of family formation reflected upward moves on the housing ladder, responding to widespread beliefs about the adequacy of housing and environmental features for family life (Lauster 2010). These mobility patterns included moving to owner-occupied housing, to larger homes in leafy neighbourhoods, or to suburban or rural areas around the time of family events (Mulder and Wagner 2001; Feijten and Mulder 2002; Kulu and Vikat 2008; Lindgren 2003; Kulu 2008). ${ }^{5}$

Despite the prevalence of the adjustment perspective, research has increasingly addressed wider interdependencies between family life courses and spatial mobility. Thus, it has acknowledged that the associations are more complex than initially thought, for instance, recognising the (involuntary) effects of spatial mobility on family life courses (Aybek, Huinink, and Muttarak 2014; Wagner and Mulder 2015). Some research evidence suggests that when spatial mobility is disruptive, unintentional, or selective, it probably has consequences for family formation and stability (Huinink and Wagner 1989; Kulu 2005; Kulu and Washbrook 2014). There is also evidence of complex time dependencies between family events and relocation events (Feijten and Mulder 2002; Clark and Withers 2009; Vidal, Huinink, and Feldhaus 2017). Familyinduced relocations may occur well in advance of the observed family event (anticipation); in addition, relocations may have consequences for family life courses later on (adaptation). Although initially family events were exclusively considered to affect housing relocations over short distances (a.k.a. residential mobility), more recently, the family's role in long-distance relocations (a.k.a. migration) has been acknowledged (Clark and Withers 2007).

Another area receiving rising attention relates the emerging patterns and outcomes of spatial mobility to family change over recent decades (Coulter, van Ham, and Findlay 2016). High levels of family instability have increased the rates of mobility due to divorce and separation (Mulder and Malmberg 2011; Cooke, Mulder, and Thomas 2016; Mikolai and Kulu 2018). The associated economic difficulties and family obligations (e.g., joint custody) have generated gendered and spatially constrained forms of mobility for separated adults, which deserve further attention (Mulder and Malmberg 2011; Feijten and van Ham 2013). There are also growing numbers of children with separated parents who move often in a multilocal family context (Mulder and Wagner 2010). It follows that increased mobility in childhood is associated with children's outcomes and can contribute to the reproduction of cycles of disadvantage (Vidal and Baxter 2018).

\footnotetext{
${ }^{5}$ Studies have also addressed the timing and patterns of relocations associated with leaving and returning to the parental home, and how these factors differ by gender and are associated with life course events, including the start and end of coresidential unions (Mulder and Clark 2002; Blaauboer and Mulder 2010). Research suggests that when individuals move in with (or marry) a partner, mobility patterns are gendered, with women more likely to move than men (Mulder and Wagner 1993; Brandén and Haandrikman 2018).
} 
Relatedly, family ties outside the household are increasingly part of the analysis of spatial mobility (Mulder and Cooke 2009). Growing family instability and diversity imply that close family members increasingly live elsewhere (e.g., separated parents and young children). In addition, social support and solidarity often occurs among family members living in different households (e.g., between parents and adult children). Family members outside the household therefore play an important role in mobility decision-making, as they can trigger or restrict mobility, acting as an attraction factor when living elsewhere or as a constraint on mobility when living close by (Hedman 2013; Mulder and Wagner 2012; Mulder and Malmberg 2014; Ermisch and Mulder 2018). Such family members are also relevant to the consequences of mobility, as moving away from or closer to family ties can limit or enhance material and emotional support. While research in this area was launched with scant theoretical knowledge, it has resulted in substantive findings and influenced recent proposals to conceptualise and properly address the linked lives of family members living elsewhere, in theoretical models of spatial mobility (e.g., Coulter, van Ham, and Findlay 2016; Mulder 2018, SC24-2).

The new diversity of family arrangements is also reflected in increasing numbers of couples who, for job-related reasons, live in separate locations or travel frequently. Research is starting to address the features and patterns of these specific types of couples (Schneider and Meil 2008; van der Klis and Karsten 2009; Reuschke 2010; Krapf 2018). Commuting to work (over a relatively long distance) is the most common type of circular mobility and is often used by members of families who increasingly prefer to remain in their homes. The scant existing research in this area has found that long-distance commuting displays gendered patterns and has relevant implications for family life courses (Huinink and Feldhaus 2012). A common finding is that women are more spatially constrained than men due to their domestic roles, which is evidenced in their shorter average commuting distances (Rapino and Cooke 2001). Long-distance commuting is more common among childless women than mothers (Hofmeister and Schneider 2010) and leads to fertility postponement among women (Meil 2010; Huinink and Feldhaus 2012). Previous studies have also found a negative association between long-distance commuting and partnership satisfaction and stability (Feldhaus and Schlegel 2013; Sandow, Westerlund, and Lindgren 2014; Kley 2015).

\subsection{Gender inequality in couple-household mobility}

A large body of research has examined long-distance relocations of couple households (a.k.a. family migration) as a site for gender inequality in the labour market and in the division of household labour. (A review of this literature can be found in Cooke 2008a.) 
Research has examined the role of the labour market resources of partnered men and women as both triggers and outcomes of couple relocations. This focus on labour market features responds to the fact that long-distance relocations are often assumed to be economically motivated and that it is unlikely that the two partners will find wellmatched jobs in the same location; thus, one partner is likely to suffer post-relocation job losses. Overall, research findings suggest that, despite increasing gender equality in the labour market, partnered women and mothers find migration a poor mechanism for advancing their occupational career (Cooke 2008a). These findings are based on overwhelming evidence showing, first, that partnered women are less likely to initiate job-related relocations than partnered men, and secondly, that relocations are associated with reduced employment rates, work hours, earnings, and occupational status, while the opposite is true for partnered men and unpartnered women (Boyle et al. 2001; Clark and Huang 2006; Cooke et al. 2009; Boyle, Feng, and Gayle 2009; Tenn 2010).

Following a human capital perspective, the tied migration hypothesis emerged as a persuasive explanation for couple relocation processes (Mincer 1978): One partnerthe lead migrant - initiates a relocation if benefits (in terms of earnings and overall household income) exceed the costs of relocation, while the other partner - the tied migrant-follows, despite potential penalties to her own career. Although the explanation is gender neutral in itself, partnered women were assumed to be the tied migrants in earlier studies, due to their more limited occupational opportunities, arising from traditional gendered divisions of labour (Halfacree 1995). These studies argued that the steady migration decline observed in contexts of increasing female labour force participation could be explained by the convergence of women's and men's resources, reducing couple households' capacity to maximise their income through relocations (DaVanzo 1976; Sandell 1977; Mincer 1978). As a result, couple households were less mobile than single-person households due to an increase in the numbers of tied stayers: partnered individuals who do not relocate for job opportunities but would have relocated had they been single (Cooke 2013).

Almost exclusively addressing the tied migration hypothesis, additional research offered further insights into gendered decisions and outcomes. Research has shown that the (relative) labour market resources of partnered men were more important predictors of couple migration than those of women, and that partnered women with higher labour market resources suffered important career losses after relocations (Lichter 1980, 1983; Markham and Pleck 1986; Jürges 2006; Shauman and Noonan 2007; Boyle et al. 2008; Tenn 2010). To explain these results, the gender role perspective proposed that the gender ideology of partners nuanced the human capital effect (Shihadeh 1991; Bielby and Bielby 1992; Cooke 2008a). ${ }^{6}$ Some evidence of an association between measures of

${ }^{6}$ The tied migration effect is gender neutral only if partners attribute similar value to the educational and
occupational resources of the male and female partners. This restriction does not apply when couples adhere 
gender ideology and couple migration behaviour and outcomes has been found (Cooke 2008b; Brandén 2014; Lersch 2016); however, this evidence cannot explain all of the observed gender asymmetries regarding the relevance of each partner's resources.

Recent studies have suggested that conclusions from existing research on the relationship between gender and couples' relocations are premature, given that relevant factors have been omitted, including the need to properly account for the role of each partner's resources and gender norms in collective decision-making processes, as proposed in bargaining theories (Lundberg and Pollack 2003; Abraham, Auspurg, and Hinz 2011), as well as for couples' selective migration (Cooke and Bailey 1996; Boyle et al. 2008). The context-level normative beliefs and structural opportunities in which these decision-making processes are embedded need to be addressed as well. Recent research has tackled some of these contextual factors, including occupational conditions (Shauman and Noonan 2007; Benson 2014), sex-typed occupations (Perales and Vidal 2013), employment discrimination (Brandén, Bygren, and Gähler 2018), social relationships (Mulder 2007; Coulter, van Ham, and Findlay 2016), regional socioeconomic structures (Nisic 2010; Zaiceva 2010; Nisic and Melzer 2016), and welfare institutions and gender cultures (Boyle et al. 2001; Vidal et al. 2017), among others.

More importantly, the literature is progressively recognising its neglect of the family and is increasingly delving into the role of family dynamics and contexts to understand gendered mobility decisions and outcomes (Bayley and Boyle 2004; Cooke 2008a). Parental status arises as a relevant predictor of gendered couple migration processes. This result is in line with ideas and empirical findings that suggest that couples are more likely to adopt traditional gender roles with parenthood. In fact, research suggests that the employment and earnings penalties following couple relocations are short-lived for childless women but persist for mothers (Cooke 2001). Advocating for the centrality of family in migration processes, Cooke (2008a) highlighted some research directions that are proving to be relevant to our understanding of mobility decision-making and outcomes for men and women. These new directions include the role of the timing of family life events (i.e., marriage, childbirth, union dissolution) for employment outcomes (De Jong and Roempke Graefe 2008); the instability of families and the new diversity of family lives (Boyle et al. 2008); the broader context of social and family ties outside households (Michielin and Mulder 2008; Mulder and Malmberg 2014); and aspects of the private sphere or quality of life (Withers, Clark, and Ruiz 2008; Nowok et al. 2013; Vidal, Perales, and Baxter 2016). These and other emerging research avenues suggest that men's and women's

to traditional gender ideology because they attribute less importance to the educational and occupational resources of the female partner. 
mobility decisions and outcomes are deeply embedded in family processes, and in more complex ways than previously thought.

\subsection{Further avenues}

What promising research avenues could improve our understanding of family and gender relations as embedded in spatial mobility patterns, decisions, and outcomes?

First, more research should be devoted to understanding why families do not move, offering a better conceptualisation of immobility and integrating alternatives to relocation into analyses. Research has consistently found that partnered individuals and parents are less mobile than unpartnered and childless individuals. This finding is consistent with the idea that the economic and social costs of spatial mobility are larger for families, which - combined with increasing equality in the labour market resources of partners - contributes to the 'tied stayer' effect by limiting the spatial mobility of partners who would like to move. Cooke (2013) argues that tied stayers do not necessarily share the same qualities and outcomes as other immobile individuals. Identifying and understanding the consequences of not moving for tied or involuntary stayers is important for understanding the effects of migration (and its negative consequences for tied or involuntary migrants), as compared to staying put.

Despite the relative residential stability of families, not relocating is not equivalent to immobility. Empirical research requires broader concepts and measures of spatial mobility that address its many forms, beyond residential relocations, in order to understand its associations with partnership and family dynamics (see Wagner and Mulder 2015). While the associations between family-related events and men's and women's residential relocations have been extensively studied, the associations between family events and commuting, and the implications of commuting for families, both remain largely under-researched (Huinink and Feldhaus 2012). Although, in itself, the study of circular mobility is relevant, studies should also explore the extent to which circular mobility functions as an alternative or complement to relocation in the context of gender and family relations (see, e.g., Melzer and Hinz 2019, SC24-3).

Second, more research is needed to clarify migration decision-making processes within families and in relation to family lives and contexts. One limitation of our understanding of gender differences in spatial mobility and its outcomes relates to the focus of research on observed behaviour, while neglecting prior decision-making processes. Desiring, considering, intending, expecting, or planning to move are steps in mobility decision-making processes that intersect with gender as well as with family status (Kley 2010; Coulter, van Ham, and Feijten 2011). Recent findings suggest that an individual's willingness to move changes over the life course, and that willingness to 
move conditions moving behaviour when coupled with family (and other) life course events (Coulter and Scott 2015; Kley 2017). A fruitful approach to understanding these interdependencies combines a theory of multidimensional life courses with decisionmaking perspectives (Huinink and Kohli 2014; Bernardi, Huinink, and Settersten 2018). Empirically, research is starting to simultaneously address the decision-making processes of mobility and family life courses, showing, for instance, that spatial mobility can be understood as a by-product of fertility intentions (Vidal, Huinink, and Feldhaus 2017).

In addition, an individual's willingness to move needs to be integrated in the multi-actor context where mobility decisions are made, i.e., by family members and in relation to other family members. Analyses show that divergent moving intentions within households have consequences for subsequent moving behaviour (Coulter, van Ham, and Feijten 2012). Despite this finding, research has only just started to explore the complexity of collective decisions by integrating bargaining models that consider the allocation of material and immaterial resources and the distribution of bargaining power among household members (Lundberg and Pollack 2003; Abraham, Auspurg, and Hinz 2013). Initial evidence suggests that mobility and immobility decisions respond not only to (immediate) costs of family relocations but also to the distribution of these costs (in the longer term) across household members (Abraham, Bähr, and Trappmann 2019, SC24-5).

Third, if we are to improve our understanding of mobility decisions and outcomes, research should move beyond the household and put the wider context of social relationships centre stage. Previous research has confirmed the relevance of nonresidential family ties for spatial mobility. However, more research evidence is needed given that demographic patterns (i.e., aging populations, increased family instability) and social change (i.e., rising economic inequality, welfare retrenchment) suggest increasing reliance on social support outside the household. Spatial mobility should be reframed in relational terms (Coulter, van Ham, and Findlay 2016). Accordingly, we should introduce wider family constellations into theories of spatial mobility (Mulder 2018, SC24-2), offering a broader conceptual orientation to address the role of contemporary family and gender relations in patterns such as the circular relocation of children in multilocal family arrangements, living apart together and shuttling partnerships, and the role of immobility in the formation and maintenance of social relationships.

Fourth, more attention should be paid to the organisation of families and the private sphere, and their relevance to spatial mobility. Although most family migration research has focused on the labour market motivations and outcomes of spatial mobility, young families often enact spatial mobility to improve work-family balance and family life (Kley 2010). It has been suggested that women may see compensation 
in the private sphere for the career losses that they experience as tied migrants (Withers and Clark 2006). Conversely, the labour market losses that tied migrants suffer could also extend to aspects of the private sphere. Despite its importance for shaping family and gender relations, the private sphere remains relatively untouched in spatial mobility research. More knowledge needs to be accumulated regarding the role of social relationships, relationship quality, life satisfaction, the division of household work, and family attitudes, to name just a few of the current gaps (see, e.g., Nisic and Kley 2019, SC24-4; Vidal and Lersch 2019, SC24-7).

Fifth and lastly, research should utilise the increasing availability of longitudinal data to address long-term trajectories. Despite some recognition in the literature of repeated mobility spells (DaVanzo 1981; McHugh, Hogan, and Happel 1995), most conceptual models ignore the wider sequence of mobility events and practices that individuals undertake over the life course (Coulter and van Ham 2013). By studying mobility trajectories, rather than discrete relocation events, research can improve our understanding of mobility processes in a biographical context (Bailey 2009) and in relation to family transitions over the life course (Vidal and Lutz 2018), and also bring attention to the linked life courses of family ties (Kõu, Mulder, and Bailey 2017). The analysis of trajectories supports research on the relevance of sustained residential stability, frequent mobility, and other early life contingencies for later life outcomes (Bernard and Vidal, forthcoming), including their role in the perpetuation of disadvantage through cumulative mobility processes, such as gender inequalities, following repeated family moves.

\section{Contents of the SC}

The SC consists of seven articles, including this introduction, a conceptual article that also presents a research agenda, and five pieces of novel empirical research.

The paper written by Clara H. Mulder titled Putting family centre stage: Ties to non-resident family, internal migration and immobility (Mulder 2018, SC24-2) offers a critical literature review and introduces new perspectives to advance research, from theoretical and empirical standpoints, on the intersections between spatial mobility (and immobility) and ties to family. Assuming that geographical proximity is crucial to family support, Mulder proposes to extend the cost-benefit approach of migration by considering ties to family living outside the household. She calls this new approach the 'family ties perspective' and argues that bias affects estimates of labour market outcomes regarding spatial mobility that do not account sufficiently for extended family contexts. In addition, Mulder discusses persuasive ideas about how spatial mobility and immobility are related to the linked lives of family members, and how these 
relationships vary across life course stages and social contexts. Finally, by presenting ideas for an appropriate research agenda, Mulder lays the groundwork for future research aiming to reveal the associations and underlying mechanisms that link family contexts with spatial mobility.

In their paper titled The role of education and educational-occupational mismatches in decisions regarding commuting and interregional migration from eastern to western Germany, Silvia M. Melzer and Thomas Hinz exploit a rich longitudinal dataset (i.e., the Socio-Economic Panel, 1992-2013) to address East Germans' rationales for spatial mobility towards economically-thriving West Germany (Melzer and Hinz 2019, SC24-3). The authors present insightful results regarding the role of education, job market match, and geographical distance for immobility, commuting, and interregional migration. In their multilevel multinomial regressions, they find different patterns of mobility for higher educated compared to lower educated people. The former prefer migrating, whereas the latter prefer commuting. Interestingly, an educational-occupational mismatch immobilises men but corresponds with an increase in commuting rates among women. The findings illustrate the importance of the joint study of commuting and interregional migration, enriching our knowledge of multiple patterns of spatial mobility.

Following on from the study of commuting and relocation behaviour, and building on the relevance of extended family and non-kin relations, Natascha Nisic and Stefanie Kley, in their paper titled Gender-specific effects of commuting and relocation on a couple's social life, study how long-distance commuting and relocations affect couples' social relationships (Nisic and Kley 2019, SC24-4). Using longitudinal data from the British Household Panel Survey (1992-2008), their fixed-effects regression models yield a highly gender-differentiated picture, with notable differences between female and male partners. In accordance with the 'tied mover' model, they show that longdistance moves detrimentally affect the quantity and quality of women's social relationships, whereas men's social relationships are not substantively affected. The effect of commuting is again different for men and women and depends on job characteristics like qualification level (women) and workload (men). In line with arguments about domesticity and the role of women as kin keepers and managers of social relationships, the authors discuss these and other relevant results. These findings shed further light on gender asymmetries in the outcomes of couples' spatial mobility that spill over into areas of life beyond the labour market.

The study by Martin Abraham, Sebastian Bähr, and Mark Trapmann revisits the question of why partnered women persistently migrate less for a job than partnered men and single women. This innovative article titled Gender differences in willingness to move for interregional job offers examines the differences between men and women when assessing the attractiveness of a job-related household move (Abraham, Bähr, and 
Trappmann 2019, SC24-5). Using various collections of data and an experimental research design, the authors present insights into the results of empirical tests. These insights provide evidence for basic differential mobility decisions among partnered women, who show a lower willingness to move than partnered men or single women. Factors proposed by standard theories (particularly regarding gender norms) predict part, but not all, of the gender gap among partnered individuals in willingness to move. Findings from this research thus suggest a need for further theoretical development to explain the persistence of gender gaps in family migration decisions and outcomes.

Studies unpacking the persisting gender inequalities that follow family moves have often focused on long-distance relocations, but most moves in connection with starting a family occur over short distances. These moves place young families in suburban or rural neighbourhoods and increase commuting distances. To examine the outcomes of residential relocation for first-time mothers according to reasons for moving, Stefanie Kley and Sonja Drobnic ask the question, Does moving for family nest-building inhibit mothers' labour force (re-)entry? (Kley and Drobnic 2019, SC24-6). Using German longitudinal data from the Socio-Economic Panel (1999-2014) and event-history analysis, they find strong evidence for the hypothesis that moving around first childbirth and family nest-building lowers the likelihood of mothers' re-entry into employment. Ironically, this finding is particularly true for returning to part-time jobs. The exception is mothers with a low earning potential who move into a newly-bought house with their family and have to work full time, presumably for financial reasons. The findings highlight the significance of family processes as mechanisms for persisting gender inequalities in the labour market following under-researched shortdistance relocations.

The concluding contribution is the article by Sergi Vidal and Philipp Lersch, titled Changes in gender role attitudes following couples' residential relocations (Vidal and Lersch 2019, SC24-7). It addresses the question of whether couples' relocations, and the related decision-making contexts and life course situations, trigger changes in attitudes towards motherhood and female employment, a.k.a. gender role attitudes. Using fixed-effects regression models to analyse the British Household Panel Survey (1991-2007), a rich longitudinal dataset that follows individuals and their partners over time, the authors find that gender role attitudes are not significantly altered following a couple's relocation. As an exception, they find that when couples exclusively relocated for the female partner's job, men's gender role attitudes became more egalitarian, postrelocation. Preliminary evidence also suggests that women's gender role attitudes are potentially affected by their exposure to residential contexts. The article builds on and contributes to the emerging literature on the stalling of the gender revolution and adds to knowledge on the under-researched sources of change within life courses. 
Altogether, this SC highlights the importance of and expands our knowledge on the interplay between family, gender, and spatial mobility. We call for more efforts that put family and gender relations centre stage in spatial mobility research. Given that spatial mobility is significantly intertwined with emerging family diversity and pervasive gender inequalities, such research advancements are key to informing policies and discussions regarding existing and future societal models.

\section{Acknowledgements}

We acknowledge funding towards the organization of the symposium "Spatial mobility, family dynamics and gender inequalities" from the German Research Foundation (grant number: VI 711/1-1). Sergi Vidal also acknowledges financial support from the Spanish Ministry of Economy and Competitiveness (grant number: RYC-2015-18254).

We would like to thank Tim Schröder, Daniela Hög, Ilona Bartkowski, and student assistants and participants in the symposium for making the collection of papers possible. We are also grateful to the Editor-in-Chief and the editorial office of Demographic Research for their invaluable assistance, and to the anonymous reviewers for their constructive comments and suggestions. 


\section{References}

Abraham, M., Auspurg, K., and Hinz, T. (2011). Migration decisions within dual-earner partnerships: A test of bargaining theory. Journal of Marriage and Family 73(4): I-III. doi:10.1111/j.1741-3737.2011.00868.x.

Abraham, M., Bähr, S., and Trappmann, M. (2019). Gender differences in willingness to move for interregional job offers. Demographic Research 40(53): 1537-1602. doi:10.4054/DemRes.2019.40.53.

Aybek, C.M., Huinink, J., and Muttarak, R. (2014). Spatial mobility, migration, and living arrangements. Dordrecht: Springer. doi:10.1007/978-3-319-10021-0.

Bailey, A.J. (2009). Population geography: Lifecourse matters. Progress in Human Geography 33(3): 407-418. doi:10.1177/0309132508096355.

Bailey, A.J. and Boyle, P. (2004). Untying and retying family migration in the New Europe. Journal of Ethnic and Migration Studies 30(2): 229-241.

Benson, A. (2014). Rethinking the two-body problem: The segregation of women into geographically dispersed occupations. Demography 51(5): 1619-1639.

Bernard, A. and Vidal, S. (forthcoming). Does migrating in childhood and adolescence affect migration behaviour in adulthood? An analysis of long-term individual migration trajectories in 11 European countries. Population, Space and Place.

Bernardi, L., Huinink, J., and Settersten, R.A. (2018). The life course cube: A tool for studying lives. Advances in Life Course Research 41: 100258. doi:10.1016/j. alcr.2018.11.004.

Bielby, W.T. and Bielby, D.D. (1992). I will follow him: Family ties, gender-role beliefs, and reluctance to relocate for a better job. American Journal of Sociology 97(5): 1241-1267. doi:10.1086/229901.

Blaauboer, M. and Mulder, C.H. (2010). Gender differences in the impact of family background on leaving the parental home. Journal of Housing and the Built Environment 25(1): 53-71. doi:10.1007/s10901-009-9166-9.

Boyle, P.J., Cooke, T.J., Halfacree, K., and Smith, D. (2001). A cross-national comparison of the impact of family migration on women's employment status. Demography 38(2): 201-213. doi:10.1353/dem.2001.0012. 
Boyle, P.J., Cullis, A., Flowerdew, R., and Gayle, V. (2003). A longitudinal analysis of the impact of family migration on women's labour market status in Britain, 1991-2000. Paper presented at the British Household Panel Survey Research Conference, Colchester, United Kingdom, July 3-5, 2003.

Boyle, P.J., Feng, Z., and Gayle, V. (2009). A new look at family migration and women's employment status. Journal of Marriage and Family 71(2): 417-431. doi:10.1111/j.1741-3737.2009.00608.x.

Boyle, P.J., Kulu, H., Cooke, T.J., Gayle, V., and Mulder, C.H. (2008). Moving and union dissolution. Demography 45(1): 209-222. doi:10.1353/dem.2008.0000.

Brandén, M. (2014). Gender, gender ideology, and couples migration decisions. Journal of Family Issues 35(7): 950-971. doi:10.1177/0192513X14522244.

Brandén, M. and Haandrikman, K. (2018). Who moves to whom? Gender differences in the distance moved to a shared residence. European Journal of Population 35(3): 435-458. doi:10.1007/s10680-018-9490-4.

Brandén, M., Bygren, M., and Gähler, M. (2018). Can the trailing spouse phenomenon be explained by employer recruitment choices? Population, Space and Place 24(6): e2141. doi:10.1002/psp.2141.

Clark, W.A.V. and Huang, Y. (2003). The life course and residential mobility in British housing markets. Environment and Planning A: Economy and Space 35(2): 323339. doi:10.1068/a3542.

Clark, W.A.V. and Huang, Y. (2006). Balancing move and work: Women's labour market exits and entries after family migration. Population, Space and Place 12(1): 31-44. doi:10.1002/psp.388.

Clark, W.A.V. and Withers, S.D. (2007). Family migration and mobility sequences in the United States: Spatial mobility in the context of the life course. Demographic Research 17(20): 591-622. doi:10.4054/DemRes.2007.17.20.

Clark, W.A.V. and Withers, S.D. (2009). Fertility, mobility and labour-force participation: A study of synchronicity. Population, Space and Place 15(4): 305-321. doi:10.1002/psp.555.

Cooke, T.J. (2001). 'Trailing wife' or 'trailing mother'? The effect of parental status on the relationship between family migration and the labor-market participation of married women. Environment and Planning A 33(3): 419-430.

Cooke, T.J. (2008a). Migration in a family way. Population, Space and Place 14(4): 255-265. doi:10.1002/psp.500. 
Cooke, T.J. (2008b). Gender role beliefs and family migration. Population, Space and Place 14(3): 163-175. doi:10.1002/psp.485.

Cooke, T.J. (2013). All tied up: Tied staying and tied migration within the United States, 1997 to 2007. Demographic Research 29(30): 817-836. doi:10.4054/ DemRes.2013.29.30.

Cooke, T.J. and Bailey, A.J. (1996). Family migration and the employment of married women and men. Economic Geography 72(1): 38-48. doi:10.2307/144501.

Cooke, T.J., Boyle, P.J., Couch, K., and Feijten, P. (2009). A longitudinal analysis of family migration and the gender gap in earnings in the United States and Great Britain. Demography 46(1): 147-167. doi:10.1353/dem.0.0036.

Cooke, T.J., Mulder, C.H., and Thomas, M. (2016). Union dissolution and migration. Demographic Research 34(26): 741-760. doi:10.4054/DemRes.2016.34.26.

Coulter, R. and Scott, J. (2015). What motivates residential mobility? Re-examining self-reported reasons for desiring and making residential moves. Population, Space and Place 21(4): 354-371. doi:10.1002/psp.1863.

Coulter, R. and van Ham, M. (2013). Following people through time: An analysis of individual residential mobility biographies. Housing Studies 28(7): 1037-1055. doi:10.1080/02673037.2013.783903.

Coulter, R., van Ham, M., and Feijten, P. (2011). A longitudinal analysis of moving desires, expectations and actual moving behaviour. Environment and Planning A: Economy and Space 43(11): 2742-2760. doi:10.1068/a44105.

Coulter, R., van Ham, M., and Feijten, P. (2012). Partner (dis)agreement on moving desires and the subsequent moving behaviour of couples. Population, Space and Place 18(1): 16-30. doi:10.1002/psp.700.

Coulter, R., van Ham, M., and Findlay, A.M. (2016). Re-thinking residential mobility: Linking lives through time and space. Progress in Human Geography 40(3): 352-374. doi:10.1177/0309132515575417.

Courgeau, D. (1985). Interaction between spatial mobility, family and career life-cycle: A French survey. European Sociological Review 1(2): 139-162. doi:10.1093/ oxfordjournals.esr.a036382.

DaVanzo, J. (1976). Why families move: A model of the geographic mobility of married couples. Santa Monica: Rand. 
Vidal \& Huinink: Introduction to the SC on spatial mobility, family dynamics, and gender relations

DaVanzo, J. (1981). Repeat migration, information costs, and location-specific capital. Population and Environment 4(1): 45-73. doi:10.1007/BF01362575..

De Jong, G.F. and Roempke Graefe, D. (2008). Family life course transitions and the economic consequences of internal migration. Population, Space and Place 14(4): 267-282. doi:10.1002/psp.506.

Ermisch, J. and Mulder, C.H. (2018). Migration versus immobility, and ties to parents. European Journal of Population 35(3): 587-608. doi:10.1007/s10680-018-94940 .

Feijten, P. and Mulder, C.H. (2002). The timing of household events and housing events in the Netherlands: A longitudinal perspective. Housing Studies 17(5): 773-792. doi:10.1080/0267303022000009808.

Feijten, P. and van Ham, M. (2013). The consequences of divorce and splitting up for spatial mobility in the UK. Comparative Population Studies 38(2): 405-432. doi:10.4232/10.CPoS-2013-10en.

Feldhaus, M. and Schlegel, M. (2013). Job-related circular mobility and the quality of intimate relationships. Comparative Population Studies 38(2): 315-340. doi:10.4232/10.CPoS-2013-07en.

Geist, C. and McManus, P.A. (2008). Geographical mobility over the life course: Motivations and implications. Population, Space and Place 14(4): 283-303. doi:10.1002/psp.508.

Halfacree, K.H. (1995). Household migration and the structuration of patriarchy: Evidence from the USA. Progress in Human Geography 19(2): 159-182. doi:10.1177/030913259501900201.

Hedman, L. (2013). Moving near family? The influence of extended family on neighbourhood choice in an intra-urban context. Population, Space and Place 19(1): 32-45. doi:10.1002/psp.1703.

Hofmeister, H. and Schneider, N.F. (2010). Job mobilities in Europe: Core findings, policy implications and future outlook. In: Schneider, N.F. and Collet, B. (eds.). Mobile living across Europe II: Causes and consequences of job-related spatial mobility in cross-national comparison. Leverkusen: Verlag Barbara Budrich: 337-356. doi:10.2307/j.ctvddzn3g.19.

Huinink, J. and Feldhaus, M. (2012). Fertility and commuting behaviour in Germany. Comparative Population Studies 37(3-4). doi:10.4232/10.CPoS-2012-05en. 
Huinink, J. and Kohli, M. (2014). A life-course approach to fertility. Demographic Research 30(45): 1293-1326. doi:10.4054/DemRes.2014.30.45.

Huinink, J. and Wagner, M. (1989). Regionale Lebensbedingungen, Migration und Familienbildung. Kölner Zeitschrift für Soziologie und Sozialpsychologie 41(4): 669-689.

Jürges, H. (2006). Gender ideology, division of housework, and the geographic mobility of families. Review of Economics of the Household 4(4): 299-323. doi:10.1007/s11150-006-0015-2.

King, R. and Skeldon, R. (2010). 'Mind the gap!' Integrating approaches to internal and international migration. Journal of Ethnic and Migration Studies 36(10): 16191646.

Kley, S. (2010). Explaining the stages of migration within a life-course framework. European Sociological Review 27(4): 469-486. doi:10.1093/esr/jcq020.

Kley, S. (2015). The impact of job-related mobility and migration intentions on union dissolution. In: Aybek, C.M., Huinink, J., and Muttarak, R. (eds.). Spatial mobility, migration, and living arrangements. Cham: Springer: 139-158. doi:10.1007/978-3-319-10021-0_7.

Kley, S. (2017). Facilitators and constraints at each stage of the migration decision process. Population Studies 71(S1): 35-49. doi:10.1080/00324728.2017.13593 28.

Kley, S. and Drobnič, S. (2019). Does moving for family nest-building inhibit mothers' labour force (re-)entry? Demographic Research 40(7): 155-184. doi:10.4054/ DemRes.2019.40.7

Kõu, A., Mulder, C.H., and Bailey, A. (2017). For the sake of the family and future: The linked lives of highly skilled Indian migrants. Journal of Ethnic and Migration Studies 43(16): 2788-2805. doi:10.1080/1369183X.2017.1314608.

Krapf, S. (2018). Moving in or breaking up? The role of distance in the development of romantic relationships. European Journal of Population 34(3): 313-336. doi:10.1007/s10680-017-9428-2.

Kulu, H. (2005). Migration and fertility: Competing hypotheses re-examined. European Journal of Population 21(1): 51-87. doi:10.1007/s10680-005-3581-8.

Kulu, H. (2008). Fertility and spatial mobility in the life course: Evidence from Austria. Environment and Planning A: Economy and Space 40(3): 632-652. doi:10.1068/ a3914. 
Kulu, H. and Milewski, N. (2007). Family change and migration in the life course: An introduction. Demographic Research 17(19): 567-590. doi:10.4054/DemRes. 2007.17.19.

Kulu, H. and Vikat, A. (2008). Fertility differences by housing type: An effect of housing conditions or of selective moves. Demographic Research 17(26): 775802. doi:10.4054/DemRes.2007.17.26.

Kulu, H. and Washbrook, E. (2014). Residential context, migration and fertility in a modern urban society. Advances in Life Course Research 21: 168-182. doi:10.1016/j.alcr.2014.01.001.

Lauster, N.T. (2010). Housing and the proper performance of American motherhood, 1940-2005. Housing Studies 25(4): 543-557.

Lersch, P.M. (2016). Family migration and subsequent employment: The effect of gender ideology. Journal of Marriage and Family 78(1): 230-245. doi:10.1111/ jomf.12251.

Lichter, D.T. (1980). Household migration and the labor market position of married women. Social Science Research 9(1): 83-97. doi:10.1016/0049-089X(80)90 $010-1$.

Lichter, D.T. (1983). Socioeconomic returns to migration among married women. Social Forces 62(2): 487-503. doi:10.1093/sf/62.2.487.

Lindgren, U. (2003). Who is the counter-urban mover? Evidence from the Swedish urban system. International Journal of Population Geography 9(5): 399-418. doi:10.1002/ijpg.296.

Lundberg, S. and Pollak, R.A. (2003). Efficiency in marriage. Review of Economics of the Household 1(3): 153-167. doi:10.1023/A:1025041316091.

Markham, W.T. and Pleck, J.H. (1986). Sex and willingness to move for occupational advancement: Some national sample results. Sociological Quarterly 27(1): 121143. doi:10.1111/j.1533-8525.1986.tb00253.x.

McHugh, K.E., Hogan, T.D., and Happel, S.K. (1995). Multiple residence and cyclical migration: A life course perspective. The Professional Geographer 47(3): 251267. doi:10.1111/j.0033-0124.1995.00251.x.

Meil, G. (2010). Geographic job mobility and parenthood decisions. Zeitschrift für Familienforschung/Journal of Family Research 22(2): 171-195. 
Melzer, S.M. and Hinz, T. (2019). The role of education and educational-occupational mismatches in decisions regarding commuting and interregional migration from eastern to western Germany. Demographic Research 41(16): 461-476. doi:10.4054/DemRes.2019.41.16.

Michielin, F. and Mulder, C.H. (2008). Family events and the residential mobility of couples. Environment and Planning A: Economy and Space 40(11): 2770-2790. doi:10.1068/a39374.

Mikolai, J. and Kulu, H. (2018). Short-and long-term effects of divorce and separation on housing tenure in England and Wales. Population Studies 72(1): 17-39. doi:10.1080/00324728.2017.1391955.

Mincer, J. (1978). Family migration decisions. Journal of Political Economy 86(5): 749-773. doi:10.1086/260710.

Mulder, C.H. (2007). The family context and residential choice: A challenge for new research. Population, Space and Place 13(4): 265-278. doi:10.1002/psp.456.

Mulder, C.H. (2018). Putting family centre stage: Ties to nonresident family, internal migration, and immobility. Demographic Research 39(43): 1151-1180. doi:10.4054/DemRes.2018.39.43.

Mulder, C.H. and Clark, W.A. (2002). Leaving home for college and gaining independence. Environment and Planning A: Economy and Space 34(6): 981999. doi:10.1068/a34149.

Mulder, C.H. and Cooke, T.J. (2009). Family ties and residential locations. Population, Space and Place 15(4): 299-304. doi:10.1002/psp.556.

Mulder, C.H. and Hooimeijer, P. (1999). Residential relocations in the life course. In: van Wissen, L.J.G. and Dykstra, P.A. (eds.). Population issues: An interdisciplinary focus. New York: Plenum: 159-186. doi:10.1007/978-94-0114389-9 6.

Mulder, C.H. and Malmberg, G. (2011). Moving related to separation: Who moves and to what distance. Environment and Planning A: Economy and Space 43(11): 2589-2607. doi:10.1068/a43609.

Mulder, C.H. and Malmberg, G. (2014). Local ties and family migration. Environment and Planning A: Economy and Space 46(9): 2195-2211. doi:10.1068/a130160p.

Mulder, C.H. and Wagner, M. (1993). Migration and marriage in the life course: A method for studying synchronized events. European Journal of Population 9(1): 55-76. doi:10.1007/BF01267901. 
Vidal \& Huinink: Introduction to the SC on spatial mobility, family dynamics, and gender relations

Mulder, C.H. and Wagner, M. (2001). The connection between family formation and first-time home ownership in the context of West Germany and the Netherlands. European Journal of Population 17(2): 137-164. doi:10.1023/A:1010706308 868.

Mulder, C.H. and Wagner, M. (2010). Union dissolution and mobility: Who moves from the family home after separation? Journal of Marriage and Family 72(5): 1263-1273. doi:10.1111/j.1741-3737.2010.00763.x.

Mulder, C.H. and Wagner, M. (2012). Moving after separation: The role of locationspecific capital. Housing Studies 27(6): 839-852. doi:10.1080/02673037. 2012.651109 .

Nisic, N. (2010). The tied-mover hypothesis reconsidered: Effects of household migration on the labour market success of partnered women. Kölner Zeitschrift fur Soziologie und Sozialpsychologie 62(3): 515-549. doi:10.1007/s11577-0100110-5.

Nisic, N. and Kley, S. (2019). Gender-specific effects of commuting and relocation on a couple's social life. Demographic Research 40(36): 1047-1062. doi:10.4054/ DemRes.2019.40.36.

Nisic, N. and Melzer, S.M. (2016). Explaining gender inequalities that follow couple migration. Journal of Marriage and Family 78(4): 1063-1082. doi:10.1111/ jomf.12323.

Nowok, B., van Ham, M., Findlay, A.M., and Gayle, V. (2013). Does migration make you happy? A longitudinal study of internal migration and subjective well-being. Environment and Planning A: Economy and Space 45(4): 986-1002. doi:10.1068/a45287.

Perales, F. and Vidal, S. (2013). Occupational characteristics, occupational sex segregation, and family migration decisions. Population, Space and Place 19(5): 487-504.

Rapino, M.A. and Cooke, T.J. (2011). Commuting, gender roles, and entrapment: A national study utilizing spatial fixed effects and control groups. The Professional Geographer 63(2): 277-294. doi:10.1080/00330124.2010.547790.

Reuschke, D. (2010). Job-induced commuting between two residences: Characteristics of a multilocational living arrangement in the late modernity. Comparative Population Studies 35(1): 107-134. doi:10.4232/10.CPoS-2010-04en.

Rossi, P.H. (1980). Why families move. Beverly Hills: Sage. 
Sandell, S.H. (1977). Women and the economics of family migration. The Review of Economics and Statistics 59(4): 406-414. doi:10.2307/1928705.

Sandow, E., Westerlund, O., and Lindgren, U. (2014). Is your commute killing you? On the mortality risks of long-distance commuting. Environment and Planning A: Economy and Space 46(6): 1496-1516. doi:10.1068/a46267.

Schneider, N.F. and Meil, G. (2008). Mobile living across Europe I: Relevance and diversity of job-related spatial mobility in six European countries. Leverkusen: Verlag Barbara Budrich. doi:10.2307/j.ctvddzvz7.

Shauman, K.A. and Noonan, M.C. (2007). Family migration and labor force outcomes: Sex differences in occupational context. Social Forces 85(4): 1735-1764. doi:10.1353/sof.2007.0079.

Shihadeh, E.S. (1991). The prevalence of husband-centered migration: Employment consequences for married mothers. Journal of Marriage and the Family 53(2): 432-444. doi:10.2307/352910.

Tenn, S. (2010). The relative importance of the husband's and wife's characteristics in family migration, 1960-2000. Journal of Population Economics 23(4): 13191337. doi:10.1007/s00148-009-0253-8.

van der Klis, M. and Karsten, L. (2009). Commuting partners, dual residences and the meaning of home. Journal of Environmental Psychology 29(2): 235-245. doi:10.1016/j.jenvp.2008.11.002.

Vidal, S. and Baxter, J. (2018). Residential relocations and academic performance of Australian children: A longitudinal analysis. Longitudinal and Life Course Studies 9(2): 133-156. doi:10.14301/llcs.v9i2.435.

Vidal, S. and Lersch, P.M. (2019). Changes in gender role attitudes following couples' residential relocations. Demographic Research 40(39): 1111-1152. doi:10.4054/ DemRes.2019.40.39.

Vidal, S. and Lutz, K. (2018). Internal migration over young adult life courses: Continuities and changes across cohorts in West Germany. Advances in Life Course Research 36: 45-56. doi:10.1016/j.alcr.2018.03.003.

Vidal, S., Huinink, J., and Feldhaus, M. (2017). Fertility intentions and residential relocations. Demography 54(4): 1305-1330. doi:10.1007/s13524-017-0592-0.

Vidal, S., Perales, F., and Baxter, J. (2016). Dynamics of domestic labor across shortand long-distance family relocations. Journal of Marriage and Family 78(2): 364-382. doi:10.1111/jomf.12269. 
Vidal, S., Perales, F., Lersch, P., and Brandén, M. (2017). Family migration in a crossnational perspective: The importance of within-couple employment arrangements in Australia, Britain, Germany, and Sweden. Demographic Research 36(10): 307-338. doi:10.4054/DemRes.2017.36.10.

Wagner, M. and Mulder, C.H. (2015). Spatial mobility, family dynamics, and housing transitions. Kölner Zeitschrift für Soziologie und Sozialpsychologie 67(S1): 111135. doi:10.1007/s11577-015-0327-4.

Withers, S.D. and Clark, W.A. (2006). Housing costs and the geography of family migration outcomes. Population, Space and Place 12(4): 273-289. doi:10.1002/psp.415.

Withers, S.D., Clark, W.A., and Ruiz, T. (2008). Demographic variation in housing cost adjustments with US family migration. Population, Space and Place 14(4): 305325. doi:10.1002/psp.503.

Zaiceva, A. (2010). East-West migration and gender: Is there a differential effect for migrant women? Labour Economics 17(2): 443-454. doi:10.1016/j.labeco.2009. 10.005 . 